\title{
Computer model for Vedavati ground water basin. Part 1. Well field model
}

\author{
KANDULA V N SARMA, K SRIDHARAN, A ACHUTHA RAO* and \\ C S S SARMA* \\ Department of Civil Engineering, Indian Institute of Science, \\ Bangalore 560012, India
}

*Central Ground Water Board, 2, 36th cross, 8th Block, Jayanagar, Bangalore, 560082 , India

MS received 6 March 1984; revised 23 August 1985

\begin{abstract}
It is shown that a leaky aquifer model can be used for well field analysis in hard rock areas, treating the upper weathered and clayey layers as a composite unconfined aquitard overlying a deeper fractured aquifer. Two long-duration pump test studies are reported in granitic and schist regions in the Vedavati river basin. The validity of simplifications in the analytical solution is verified by finite difference computations.
\end{abstract}

Keywords. Ground water; well field model; hard rock; leaky aquifer; computer model.

\section{Introduction}

A mathematical model for regional ground water resource evaluation has been developed for the Vedavati river basin extending over parts of Karnataka and Andhra Pradesh (figure 1). The Vedavati basin is a typical crystalline hard rock area. The studies are of particular significance as nearly $2 / 3$ rds of our country is covered by hard rock area. The Indian Institute of Science was a consultant to the Central Ground Water Board in the development of the mathematical model for the study.

Considerable development took place in numerical modelling of ground water flows in the 60 s and 70 s and finite difference models have been applied to a variety of problems like confined, semiconfined, unconfined, mixed confined-unconfined and saturated-unsaturated flow systems. A few notable studies in this field are by Freeze $\&$ Witherspoon (1966, 1967, 1968), Taylor \& Luthin (1969), Freeze (1969), Bredehoeft \& Pinder (1970), Prickett \& Lonnquist (1971), Brutsaert (1973), Cooley $(1971,1972)$ and Trescott \& Larson (1977). However, there have not been many applications of ground water modelling for regional problems in hard rock areas. There has been a constant and inconclusive debate on the applicability of porous media flow concepts for hard 


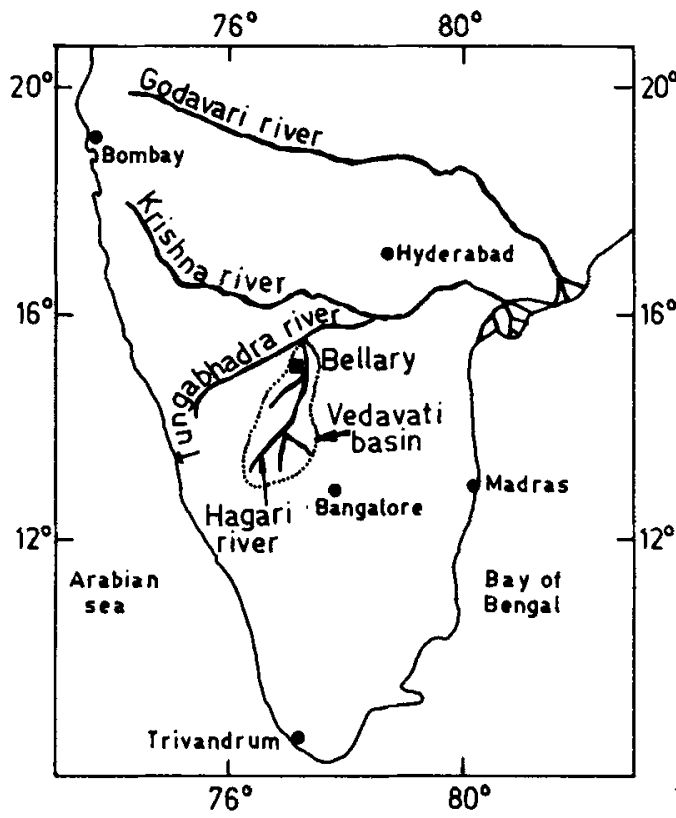

Figure 1. Location map of the Vedavati river basin.

rock aquifers (Streltsova 1976, p. 48). However, adaptations of a continuum approach have been the most promising tools from practical considerations.

Part 1 of this three part report is concerned with the development of a suitable conceptual model for hard rock aquifers. A leaky aquifer model, with an unconfined aquitard overlying a fractured aquifer is proposed. The proposed leaky aquifer model is based on experiments under pumping tests at two well fields. Part 2 describes the computer model for regional ground water resource evaluation in the basin, based on the leaky aquifer concept. The model is calibrated based on observations over one year and the calibrated model is used to determine the distribution of safe yield, overexploited regions and regions of maximum potential. The ground water potential identified in this study is used in part 3 to estimate the talukwise irrigation potential in the basin, over and above the existing utilisation. The extent of additional area that can be brought under irrigation is determined for each taluk consistent with water availability and crop water requirements.

\section{Conceptual model for hard rock aquifers}

A hard rock aquifer is essentially a complex three-dimensional ground water reservoir with fractures and less permeable blocks adjoining each other and with their geometry and hydrogeologic properties varying with depth as well as location in plan. Practical considerations, however, demand the adoption of a two-dimensional model, either the classical or the nonclassical type. Three types of two-dimensional models deserve consideration: (i) the unconfined aquifer model, (ii) the leaky aquifer model and (iii) the double permeability-storativity model. Among these, the unconfined and leaky aquifer models have been used successfully in classical porous media systems (Walton 1970), while the double permeability-storativity concept has been specifically developed for hard rock aquifers (Barenblatt et al 1960; Streltsova 1976). 
In the double permeability-storativity system, the hard rock aquifer is represented by a system of fractures with relatively high permeability, surrounded by pervious blocks whose permeability is much smaller than that of the fractures. During unsteady flow under pumping, water is first released from the fractures and this creates a pressure difference between the fractures and the blocks which causes a 'leakage' from the blocks to the fractures, as from an aquitard to the aquifer in the case of a leaky aquifer. Thus the double permeability-storativity model has considerable similarity with a leaky aquifer model. While some simple well field solutions have been obtained based on the double permeability-storativity model (Barenblatt et al 1960; Warren \& Root 1963), no regional applications have been reported.

Piezometer nest observations under pumping clearly indicate a two-layer behaviour of the aquifer, with a significantly smaller drawdown in the upper layers, like in a leaky aquifer system. While this rules out a vertically homogeneous unconfined aquifer model, the observations might also be explained by a two-layer unconfined aquifer model. The difference between the leaky and unconfined aquifers is essentially in terms of the dominant flow direction in the upper layer. If the flow direction in the upper layer is predominantly vertical, it corresponds to a leaky aquifer system, while if it is predominantly horizontal, it corresponds to a two-layer unconfined aquifer system.

\section{Leaky aquifer model}

The two-layer behaviour of the aquifer under pumping conditions suggests the adoption of a leaky aquifer model. In order to verify the validity of the model, a test was made in a schist region in the Kodigehalli well field in the West Suvarnamukhi subbasin, which lies in the southwest part of the Vedavati basin. A salt solution of known concentration was introduced in a watertable well located at a distance of $10 \mathrm{~m}$ from the pumping well (figure 2). A piezometer nest was constructed in between this watertable well and the pumping well at a distance of $5 \mathrm{~m}$ from the pumping well. The pumping well was not cased over the entire saturated zone thus permitting lateral flow in the upper zone also. In the piezometer nest, three piezometer tubes were located, one tapping the watertable zone, one tapping the deeper aquifer and one tapping the zone in between. By measuring the conductivity of the three samples, it was possible to determine the location of the path of the tracer at the piezometer nest. The salt solution

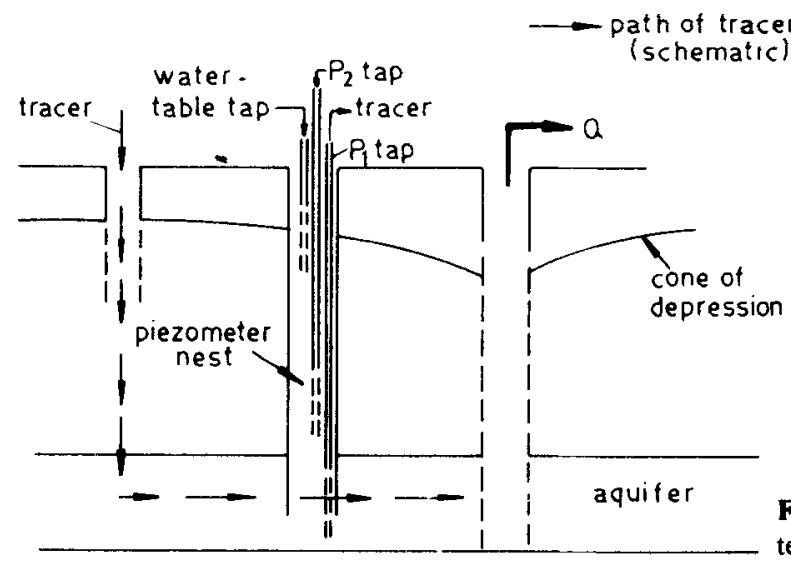

Figure 2. Schematic diagram for tracer test. 
was traced only in the $P_{1}$ tap (figure 2), indicating that the tracer introduced in the watertable zone first travelled vertically downwards and only then followed a lateral path in the deeper aquifer. This behaviour is a characteristic feature of the leaky aquifer.

The leaky aquifer behaviour was also indicated by the recovery observations after pumping was stopped. Figures 3 and 4 present observations of piezometric heads during and after a long-duration pump test. The Hardagere well field (figure 3 ) is in a granite region while the Haragonadona well field (figure 4) is in a schist region. Piezometric head observations are shown for the watertable zone, the deeper aquifer zone and the zone in between. These observations confirm that in reality, the ground water system in the Vedavati basin is a complex three-dimensional system with variations of piezometric head in the vertical direction also. However, these results also show that if a two-dimensional approximation has to be resorted to from practical considerations (it is a necessity in modelling such a large area), the leaky aquifer model is a realistic representation of the physical system.

This is further substantiated by the recovery observations shown in figures 3 and 4. Recovery in the upper zone starts only when the piezometric head in the deeper aquifer rises above the head in the upper zone initiating leakage back into the upper zone. Till then the head in the upper zone continues to decline in spite of the stoppage of pumping because of the continuing leakage from this zone into the deeper aquifer. Such behaviour is the principal feature of a leaky aquifer concept.

The leaky aquifer model used in the present study is shown schematically in figure 5 . The clayey and weathered layers above the deeper fractured aquifer are treated as a

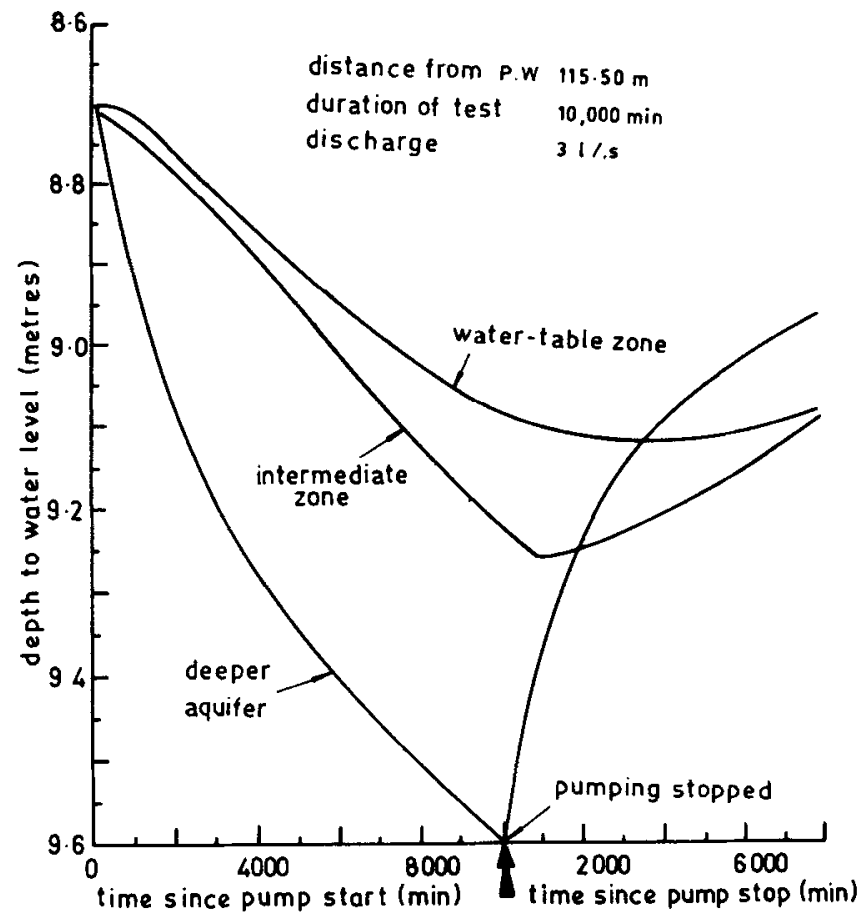

Figure 3. Drawdown and recovery observations at the Haradagere well field (PW - pumping well) 


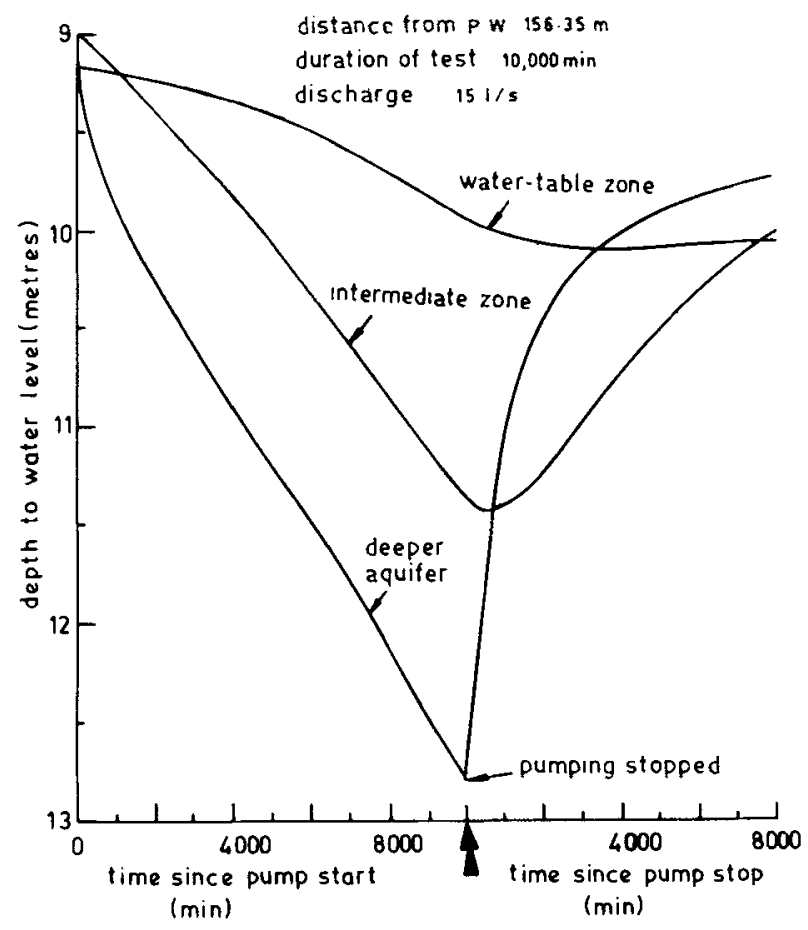

Figure 4. Drawdown and recovery observations at the Haragonadona well field.

single composite unconfined aquitard in which flow is predominantly vertical, with the transfer of water occurring between the aquitard and the aquifer termed leakage. To facilitate well field analysis, it is assumed that there is negligible change in the watertable level in the composite aquitard. With this simplification, the basic equations and boundary conditions for drawdown in the vicinity of a well pumped at constant discharge become identical to the leaky aquifer problem (figure 6) considered by

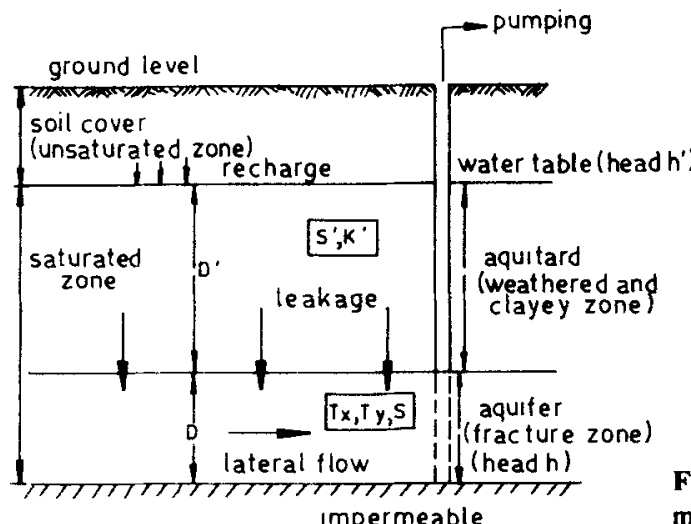

Figure 5. Schematic diagram of the leaky aquifer model. 


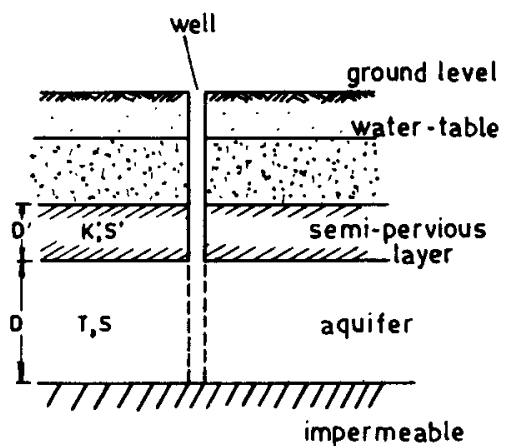

Figure 6. Leaky aquifer with storage release from aquitard.

Hantush (1964). This simplification facilitates the evaluation of the aquifer parameters based on pump test observations.

\section{Well field solution}

Pump test observations indicate a strong anisotropy, particularly in schist regions. The geological features of the Vedavati basin indicate that the principal axes run northeastsouthwest ( $x$ axis) and northwest-southeast ( $y$ axis) with the maximum transmissivity being in the $y$ direction.

With the choice of $x$ and $y$ axes along the principal axes, the unsteady state equation for the aquifer and aquitard drawdowns under constant pumping (figure 6) becomes,

$$
T_{x} \frac{\partial^{2} s}{\partial x^{2}}+T_{y} \frac{\partial^{2} s}{\partial y^{2}}+K^{\prime} \frac{\partial s^{\prime}}{\partial z}+Q \delta(x) \delta(y)=S \frac{\partial s}{\partial t}
$$

and $\quad K^{\prime} \frac{\partial^{2} s^{\prime}}{\partial z^{2}}=\frac{S^{\prime}}{D^{\prime}} \frac{\partial s^{\prime}}{\partial t}$

The initial and boundary conditions are given by,

$$
\begin{aligned}
t=0: & s(x, y)=0 ; s^{\prime}(x, y, z)=0 \\
t>0: & s( \pm \infty, y)=0 ; s(x, \pm \infty)=0 \\
& s^{\prime}(x, y, D)=s(x, y)
\end{aligned}
$$

and

$$
s^{\prime}\left(x, y, D+D^{\prime}\right)=0 \text {. }
$$

Modifying Hantush's (1964) solution for the corresponding anisotropic problem, the solution for (1)-(3) is obtained as follows.

Small time solution

$$
\begin{aligned}
& s=\left[Q / 4 \pi\left(T_{x} T_{y}\right)^{1 / 2}\right] W_{1}(u, \psi), \\
& u=(S / 4 t)\left[T_{x} y^{2}+T_{y} x^{2} / T_{x} T_{y}\right), \\
& \psi=\frac{1}{4}\left[\left(T_{x} y^{2}+T_{y} x^{2}\right) / T_{x} T_{y}\right]^{1 / 2}\left[\left(S^{\prime} / S\right)\left(K^{\prime} / D^{\prime}\right)\right]^{1 / 2}
\end{aligned}
$$


Large time solution

$$
\begin{aligned}
& s=\left[Q / 4 \pi\left(T_{x} T_{y}\right)^{1 / 2}\right] W_{2}\left(u^{\prime}, \eta\right), \\
& u^{\prime}=(S / 4 t)\left[1+\left(S^{\prime} / 3 S\right)\right]\left[\left(T_{x} y^{2}+T_{y} x^{2}\right) / T_{x} T_{y}\right], \\
& \eta^{2}=\left[\left(T_{x} y^{2}+T_{y} x^{2}\right) / T_{x} T_{y}\right] K^{\prime} / D^{\prime}
\end{aligned}
$$

The well functions $W_{1}$ and $W_{2}$ in (4) and (7) are given by (Hantush 1964):

$$
\begin{aligned}
& W_{1}(u, \psi)=\int_{u}^{\infty}[\exp (-y) / y] \operatorname{erfc}\left\{u^{1 / 2} /[y(y-u)]^{1 / 2}\right\} \mathrm{d} y, \\
& W_{2}\left(u^{\prime}, \eta\right)=\int_{u^{\prime}}^{\infty}\left[\exp \left(-y-\eta^{2} / y\right) / y\right] \mathrm{d} y .
\end{aligned}
$$

Type curves based on the integrals in (10) and (11) are available elsewhere (Hantush 1964 , p. 282; Walton 1970) and are not presented here.

\section{Parameter estimates from well field analysis}

Analyses of long-duration ( 7 days) pump tests at two well fields, one in the granite region and the other in the schist region, are presented. The relative locations of pumping wells and observation wells are presented in figures 7 and 8. In the figures, PN refers to the piezometer nest at each observation well. The pumped discharge was $31 / \mathrm{s}$ at Haradagere and $15 \mathrm{l} / \mathrm{s}$ at Haragonadona.

Briefly, the analysis procedure is as follows. By matching the field drawdown at PN1 or PN2 with small time and large time type curves, match point details corresponding to $u\left(\right.$ or $\left.u^{\prime}\right), W_{1}$ (or $\left.W_{2}\right), s, t$ and $\psi$ (or $\eta$ ) are noted (Walton 1970). The matching of field data and type curves are so made that a single value is obtained for the product $T_{x} T_{y}$ from both small time and large time solutions, as well as PN1 and PN2 observations. Once the match point details are obtained, if $T_{y} / T_{x}$ is assumed, $T_{x}, T_{y}, S, S^{\prime}$ and $K^{\prime} / D^{\prime}$ can be calculated using (4)-(9). Two separate sets of estimates are obtained for the parameters
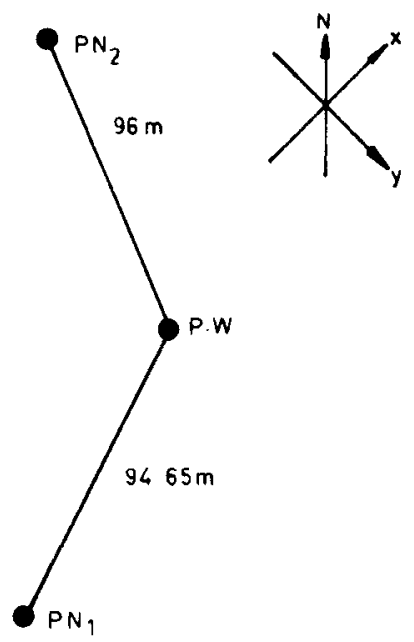

Figure 7. Well field at Haradagere. 


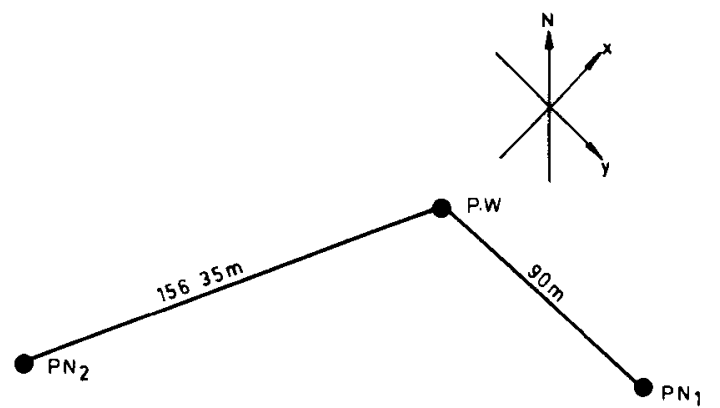

Figure 8. Well field at Haragonadona.

from PN1 and PN2 observations. By trial and error, a value of $T_{y} / T_{x}$, which will yield the closest agreement between the two sets of parameter values corresponding to PN 1 and PN2 observations, can be obtained. It is not possible to have an exact agreement for each parameter and judgement has to be used in deciding about the agreement. However, in practice, it was found that $T_{y} / T_{x}$ can be obtained with a good degree of confidence by this method. A verification of the final values of the parameters, obtained by this method, is made by comparing observed drawdown and predicted drawdown using (4)-(9).

As the upper weathered zone acts as a composite unconfined aquitard (figure 5), the value of $S^{\prime}$ obtained by the analysis may be expected to correspond to the specific yield value. It must be noted here that there is a drop in the watertable level under pumping, though this drawdown is much less than the deeper aquifer drawdown.

The parameter values, obtained from the analysis described above, for the Haradagere well field are as follows:

$$
\begin{aligned}
& T_{x}=32 \mathrm{~m}^{2} / \text { day; } T_{y}=42.6 \mathrm{~m}^{2} / \text { day } ;=2 \times 10^{-3} ; \\
& S^{\prime}=3.7 \times 10^{-2} ; K^{\prime} / D^{\prime}=2 \times 10^{-3}(\text { day })^{-1} .
\end{aligned}
$$

The parameter values obtained for the Haragonadona well field are as follows:

$$
\begin{aligned}
& T_{x}=8 \mathrm{~m}^{2} / \text { day } ; T_{y}=48 \mathrm{~m}^{2} / \text { day; } S=2 \times 10^{-6} ; \\
& S^{\prime}=1.4 \times 10^{-2} ; K^{\prime} / D^{\prime}=1.8 \times 10^{-4} \text { (day) }^{-1}
\end{aligned}
$$

Thus there is a strong anisotropy at the Haragonadona well field (schist region), while there is only mild anisotropy at the Haradagere well field (gneiss region).

\section{Discussion of results}

Figures 9 to 11 present the observed and computed drawdowns using the estimated parameters in (4)-(9). Data from only one observation well are presented for the Haradagere well field (figure 9) in view of near isotropy. Analysis was also made using Hantush's (1964) solution for the case when the aquitard is confined on the upper boundary. This model was found to give slightly better agreement, but the unconfined aquitard model (figure 5) is adopted because of convenience of application in regional studies.

Field observations indicate that the 'watertable' level is consistently above the level where water is first struck while drilling. The differences between the two levels seem to increase with increase of the depth of overburden above the watertable. This difference 


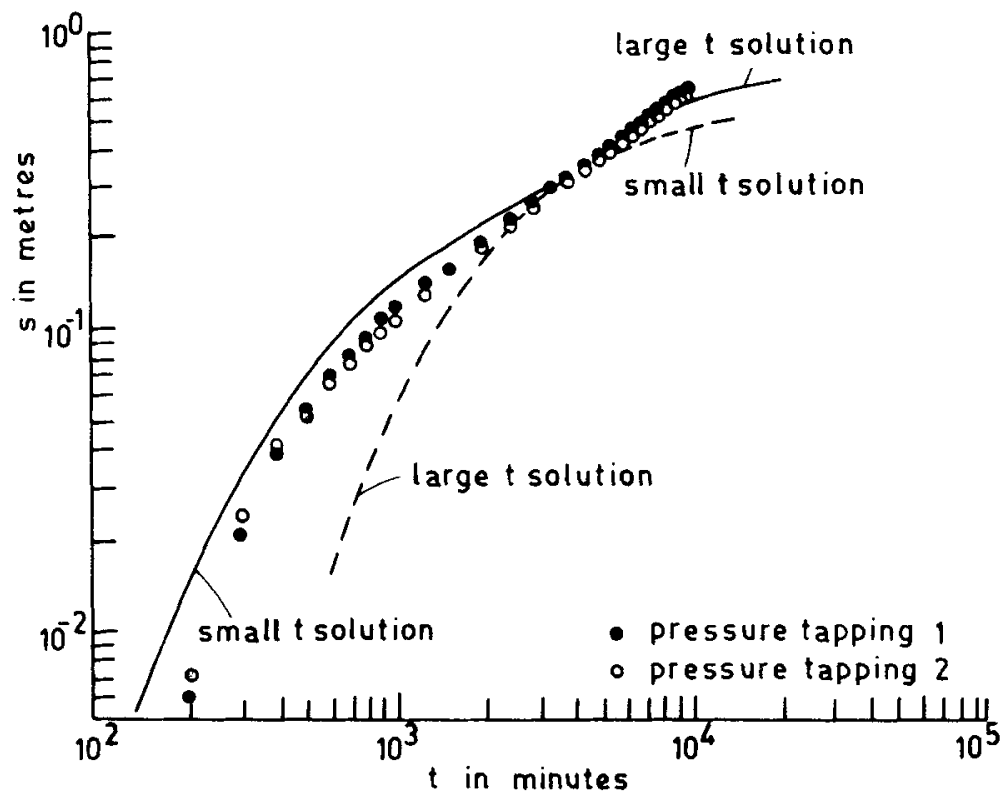

Figure 9. Drawdown at PN1 at Haradagere.

is of the order of $2 \mathrm{~m}$ in both the Haradagere and the Haragonadona well fields. These observations perhaps suggest that the so called 'watertable' zone is strictly not an unconfined zone, but could be slightly confined. However, under pumping conditions, it could quickly become unconfined. Thus the storage coefficient of the upper layer may actually change under pumping conditions, increasing towards specific yield value. In view of these uncertainties, the limits of time for the validity of the small time and large time solutions as given by Hantush (1964) are not found to hold good for the present case.

The results in figures 9-11 show that the estimated parameters can be used to simulate the drawdown reasonably well. In these figures, the analytical solutions for small time and large time are shown by solid lines where they match the field data and otherwise by broken lines. It is interesting to note that once the drawdown observations meet the large time solution, they start following its trend. Such a change in the trend of drawdown data is remarkably seen in figure 10 for the data at PN1 at the Haragonadona well field.

\section{Effect of upper layer drawdown}

The simplified model which facilitates the use of the Hantush (1964) leaky aquifer solution does not exactly correspond to the real situation as there is a drawdown in the upper layer also. In order to study the effect of the upper layer drawdown, a numerical solution based on the finite difference technique is used. The computational details are not discussed here. Results of analytical (large time solution) and finite difference solutions obtained at a hypothetical observation well located at $x=200 \mathrm{~m}, y=0$ in the Haragonadona well field are presented in figure 12. The computer simulation of 


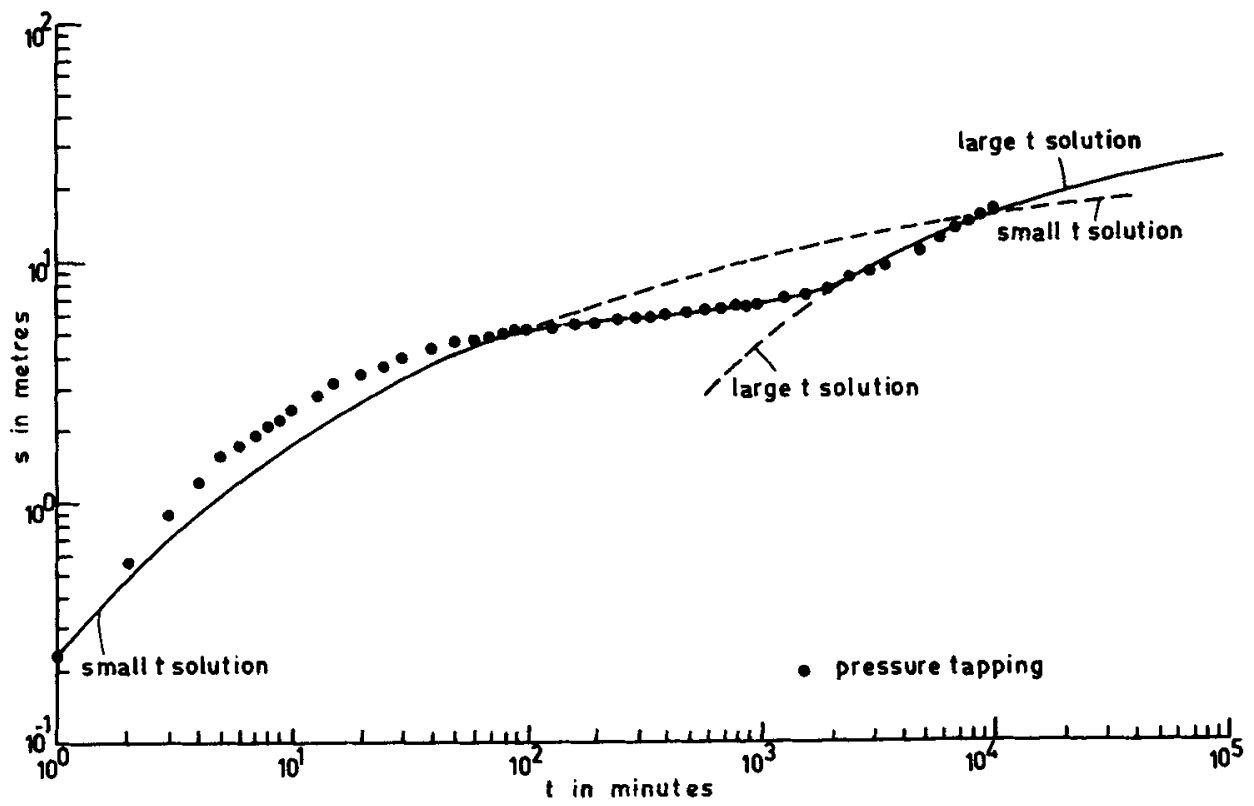

Figure 10. Drawdown at PN1 at Haragonadona.

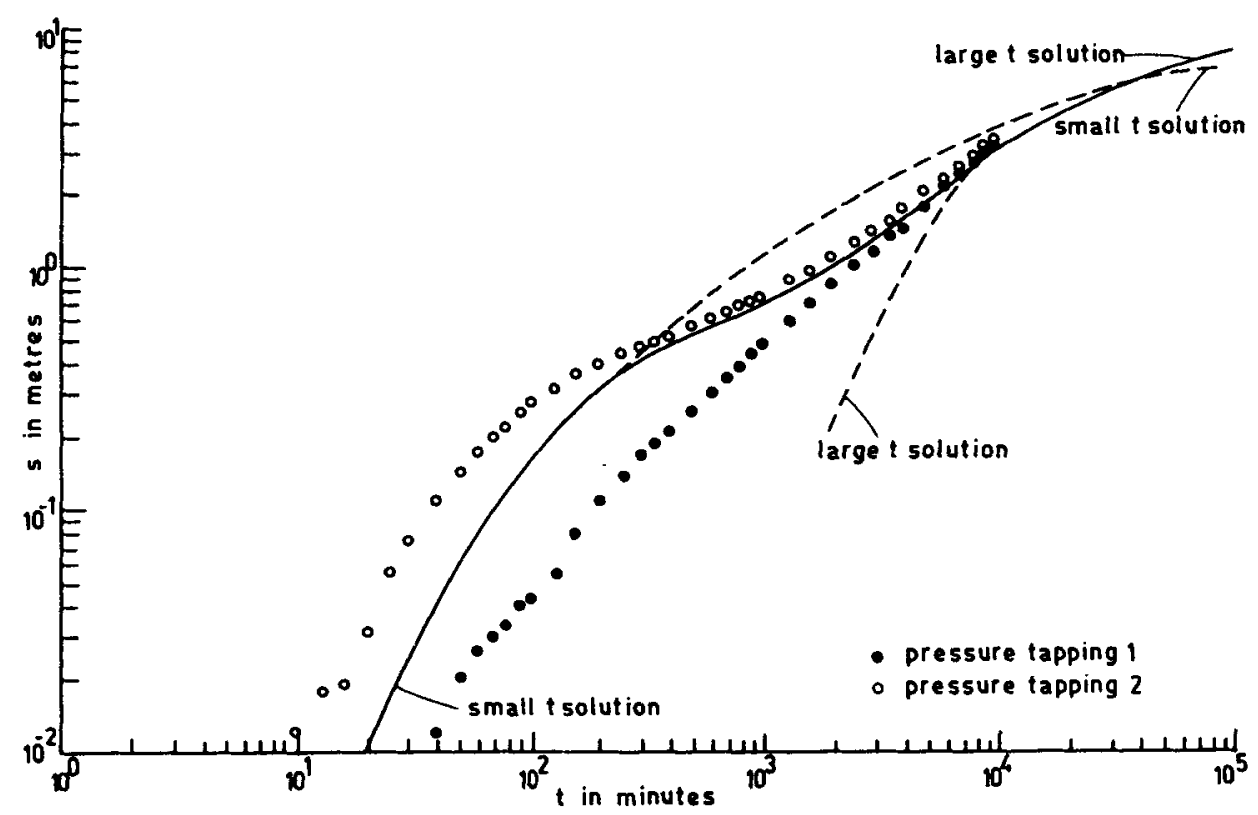

Figure 11. Drawdown at PN2 at Haragonadona. 


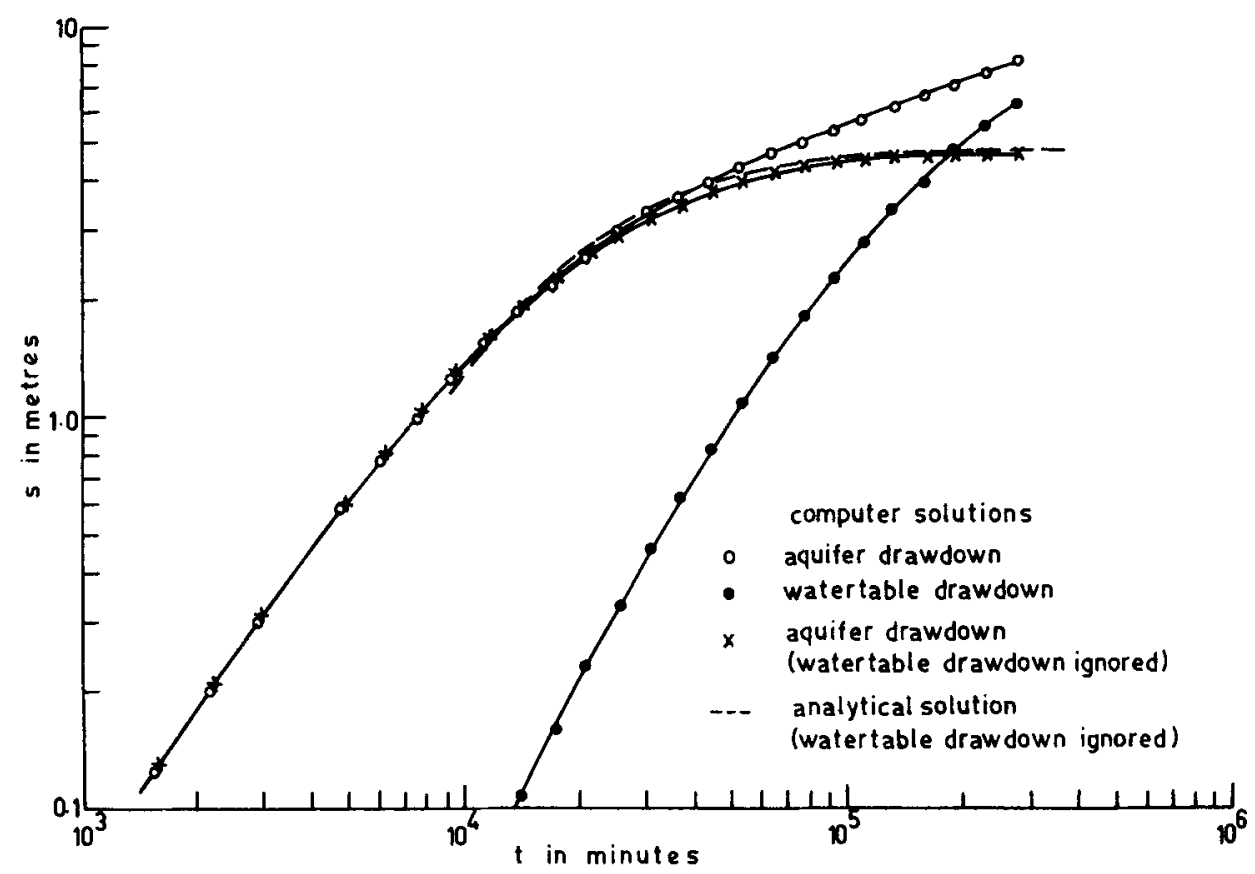

Figure 12. Effect of watertable drawdown at Haragonadona.

drawdown was done for a period of 200 days under a steady pumping of $15 \mathrm{lps}$.

It is seen from figure 12, that the effect of watertable drawdown on the deeper aquifer drawdown becomes significant only after a long duration of pumping, about 25 days in the example presented. Computations for the drawdown at the observation wells for both Haradagere and Haragonadona well fields confirm that for upto 7 days, which is the period of the pump test, the effect of watertable drawdown is not very significant. The results in figure 12 show good agreement between the large time analytical solution and the finite difference solution ignoring the watertable drawdown. The computer solution shows that as pumping continues, the watertable drawdown gradually increases and approaches the deeper aquifer drawdown. This observation is of significance in regional modelling. It must be noted that these computations for prolonged pumping have been undertaken only for illustrative purposes without placing any constraint on available drawdowns.

\section{Conclusions}

Considerations for the selection of an appropriate well field model for the hard rock aquifers of the Vedavati basin are presented. It is shown that the concept of a leaky aquifer system can be successfully used for a hard rock ground water system. A model is proposed treating the clayey and weathered upper layers as a composite unconfined aquitard over the deeper fracture aquifer. Hantush asymptotic solutions for leaky aquifers are used to obtain parameter estimates from two long duration pump tests, one in the granitic region and the other in the schist region. The effect of ignoring the upper layer drawdown in the analytical solution is studied by the finite difference method. 


\section{List of symbols}

$D, D^{\prime} \quad$ thickness of the aquifer and the aquitard, respectively,

$K^{\prime} \quad$ vertical hydraulic conductivity in aquitard,

$Q \quad$ discharge at pumping well,

$s, s^{\prime} \quad$ drawdown in the aquifer and in the aquitard, respectively,

$S, S^{\prime} \quad$ storage coefficient of the aquifer and of the aquitard (specific yield), respectively,

$t$ time,

$T_{x}, T_{y} \quad$ transmissivities in the $x$ direction and in the $y$ direction, respectively,

$u, u^{\prime} \quad$ nondimensional parameters in the drawdown solution,

$W_{1}, W_{2}$ well functions in the drawdown solution,

$x, y \quad$ space coordinates along principal axes,

$z \quad$ vertical coordinate,

$\delta($ ) Dirac delta function,

erfc complementary error function,

$\eta, \psi \quad$ parameters in well functions.

\section{References}

Barenblatt G E, Zheltov In P, Kochina 111960 J. Appl. Math. Mech. (Engl. Transl.) 24: 1286-1303

Bredehoeft J D, Pinder G F 1970 Water Resour. Res. 6: 883-888

Brutsaert W F 1973 J. Hydraul. Div., Am. Soc. Civ. Eng. 99: 1981-2001

Cooley R L 1971 Water Resour. Res. 7: 1607-1625

Cooley R L 1972 Water Resour. Res. 8: 1046-1050

Freeze R A 1969 Water Resour. Res. 5: 153-171

Freeze R A, Witherspoon P A 1966 Water Resour. Res. 2: 641-656

Freeze R A, Witherspoon P A 1967 Water Resour. Res. 3: 623-634

Freeze R A, Witherspoon P A 1968 Water Resour. Res. 4: 581-590

Hantush M S 1964 Advances in hydroscience (ed.) V T Chow (New York: Academic Press) vol. 1

Prickett T A, Lonnquist C G 1971 Selected digital computer techniques for ground water resource evaluation, Bulletin 55, Illinois State Water Survey, Urbana, USA

Streltsova T D 1976 Advances in ground water hydrology (ed.) Z A Saleem (Minneapolis: American Water Resources Association)

Taylor G S, Luthin J N 1969 Water Resour. Res. 5: 144-152

Trescott P C and Larson S P 1977 Water Resour. Res. 13: 125-136

Walton W C 1970 Ground water resource evaluation (Tokyo: McGraw-Hill, Kogakusha)

Warren J E, Root P J 1963 Soc. Pet. Eng. J. 245-255 